\title{
OS SABERES DOCENTES IDENTIFICADOS NA PRODUÇÃO ACADÊMICA NO EXERCÍCIO DA EDUCAÇÃO INCLUSIVA
}

\author{
EL CONOCIMIENTO DOCENTE IDENTIFICADO EN LA PRODUCCIÓN \\ ACADÉMICA EN EL EJERCICIO DE LA EDUCACIÓN INCLUSIVA
}

\author{
CONCEPTUAL KNOWLEDGE - AN ESSENTIAL TOOL FOR TEACHERS IN \\ INCLUSIVE EDUCATION
}

\author{
NOZI, Gislaine Semcovici \\ gislainesemcovicinozi@gmail.com \\ UEL - Universidade Estadual de Londrina \\ https://orcid.org/0000-0001-5128-0493 \\ VITALIANO, Celia Regina \\ reginavitaliano@gmail.com \\ UEL - Universidade Estadual de Londrina \\ https://orcid.org/0000-0002-8757-4204
}

\begin{abstract}
RESUMO Este estudo tem por objetivo caracterizar os saberes docentes recomendados por pesquisadores da área da Educação Especial como necessários ao professor do Ensino Regular para promover a inclusão de alunos com necessidades educacionais especiais (NEE). Realizamos uma pesquisa documental de teses e dissertações disponíveis no Banco de Teses da Capes. Os dados coletados foram organizados a partir da Análise de Conteúdo que consistiram em cinco temas: dimensão conceitual, dimensão procedimental, dimensão atitudinal, dimensão contextual e outras características pessoais do professor que favorecem a inclusão de alunos com NEE. Os resultados foram analisados à luz dos referenciais teóricos do movimento educacional inclusivo e evidenciaram que os saberes mais frequentemente indicados como necessários para a atuação pedagógica em classes inclusivas contribuem para o processo educacional de todos os alunos, sejam eles com ou sem NEE.
\end{abstract}

Palavras-chave: Educação Inclusiva. Formação de professores. Saberes Docentes.

RESUMEN Este estudio tiene como objetivo caracterizar el conocimiento docente recomendado por investigadores del área de la Educación Especial como necesario para el profesor de la enseñanza regular con el fin de impulsar el desarrollo de la inclusión de alumnos con necesidades educativas especiales (NEE). Realizamos una investigación documental de tesis y disertaciones disponibles en el banco de tesis de la Capes. Los datos recolectados fueron organizados a partir del análisis de contenido que consistieron en cinco temas: dimensión conceptual, dimensión procedimental, dimensión actitudinal, dimensión contextual y otras características personales del profesor la cuales favorecen la inclusión de alumnos con NEE. Los resultados fueron analizados en base a los referenciales teóricos del movimiento educacional inclusivo 
y evidenciaron que los saberes más frecuentemente indicados como necesarios para la acción pedagógica en clases inclusivas que contribuyen con el proceso educacional de todos los alumnos, sean ellos con o sin NEE.

Descriptores: Educación inclusiva. Formación de profesores. Conocimiento docente. ABSTRACT The aim of this paper is to characterize the knowledge recommended by researchers on the field, as a necessary skill for teachers in regular education in order to promote the inclusion of pupils with special educational needs to do so, a documental research was carried out the thesis and at Capes Theses Bank. The results obtained indicated five themes: conceptual dimension, procedural dimension, attitudinal dimension, contextual dimension and other teachers" personal characteristics which foster the inclusion of SEN students. It is also observed that the most frequent knowledge indicated as necessary for a pedagogical acting in inclusive classrooms make contributions not only to the process of the inclusion of SEN pupils but also to the educational process of all students, regardless having or not having special educational needs.

Keywords: Education Inclusion. Teacher training. Teachers' Knowledge.

\section{INTRODUÇÃO}

A idealização de uma escola inclusiva apresenta-se com muitos desafios, já que a instituição escolar é convocada a oportunizar uma educação de qualidade para todas as crianças, jovens e adultos, independentemente de suas condições físicas, biológicas, sociais, econômicas, culturais, entre outras, tendo que, para isso, ressignificar práticas pedagógicas historicamente homogeneizadoras e excludentes para, transformá-las em práticas mais dinâmicas, integradoras, colaborativas, inclusivas.

Uma das maiores dificuldades enfrentadas pela escola na implementação da educação inclusiva está relacionada à carência de formação dos professores para atuar junto aos alunos NEE, como aqueles que, sendo ou não público-alvo da Educação Especial, apresentam dificuldades de aprendizagem durante o percurso escolar na classe comum que requerem condições diversificadas para aprender das oferecidas aos demais alunos.

Miranda (2011), ao analisar pesquisas voltadas à formação docente para a educação inclusiva, constatou que são raras as que se voltam para o estudo dos saberes e práticas docentes. 
Em consideração ao interesse em desvelar os saberes docentes indicados pelos pesquisadores da área para favorecer o processo de inclusão dos alunos com $\mathrm{NEE}$, iniciamos as análises pontuando as possíveis compreensões sobre o conceito saberes docentes e o seu desenvolvimento.

O termo saberes docentes aparece na literatura da área de Educação a partir dos anos 1990, segundo Borges (2001) e Azevedo (2007), decorrente da preocupação com a qualificação profissional do professor. Em meio ao contexto que buscava fortalecer a profissionalização do professor e sua identidade, emerge "a necessidade de se especificar o saber para o ensino Knowledge base - numa tentativa de se encontrar uma identidade para profissão docente, que até então era considerada como semiprofissão" (AZEVEDO, 2017, p. 47). Os argumentos para isso derivavam da percepção de que se os demais profissionais, médicos, advogados e outros dispõem de um conjunto de saberes que os definem, em vista disso, os professores também deveriam ter explicitado os saberes necessários para a sua constituição profissional.

Conforme analisa Borges (2001), a produção sobre saberes docentes a partir dos anos 1990 tem sido extensa, bem como as concepções teóricas que as embasam, o que torna difícil encontrar um conceito único, por conseguinte, tomamos como base a definição de Tardif $(2004$, p.36) que conceitua saberes docentes como "[...] um saber plural formado pelo amálgama, mais ou menos coerente, de saberes oriundos da formação profissional e de saberes disciplinares, curriculares e experienciais". Considerando esta definição, podemos compreender que os saberes docentes estão sempre em processo de construção. Dessa forma, "[...] infere-se que os saberes docentes, enquanto temporais, plurais, heterogêneos, permeados por marcas de seres humanos, são revisáveis, criticáveis e passíveis de aperfeiçoamento [...]" (BLOCK; RAUSCH, 2014, p.251).

Tais análises permitem perceber que os saberes docentes não se constituem apenas na Formação Inicial, pois seu processo depende das experiências profissionais que cada professor vivencia, bem como de sua forma de perceber e viver no mundo (BLOCK; RAUSCH, 2014). O professor, em sua atuação pedagógica, não utiliza apenas conhecimentos científicos, há uma gama de saberes - além daqueles do campo propriamente pedagógico e curricular - que são de ordem histórica, política, 
social, cultural, pessoal, afetiva, etc., que influenciam, constroem e reconstroem os saberes dos professores a partir da prática cotidiana (NUNES, 2001).

Ao realizarmos uma revisão das teses e dissertações desenvolvidas nos últimos anos, que relacionam saberes docentes e educação inclusiva, identificamos as seguintes pesquisas de: (JESUS, 2004; DAL-FORNO,2005; GUASSELI, 2005; SANTOS, 2007; FERRAZ, 2008; CARAMÃO, 2009). No entanto, constamos que as indicações dos pesquisadores sobre os saberes necessários para a inclusão partiram de observações no contexto escolar e entrevistas com professores, levando em consideração os conhecimentos que eles julgam necessários para a atuação junto aos alunos com NEE. A análise da produção acadêmica em relação à temática ainda não havia sido realizada, o que nos motivou a investirmos na pesquisa documental para a identificação dos saberes considerados importantes aos docentes para a atuação pedagógica em contextos educacionais inclusivos.

Dessa forma, a presente pesquisa, ao caracterizar os saberes docentes recomendados por pesquisadores da área como importantes ao professor para promover a inclusão dos alunos com NEE, a partir de referenciais teóricos relacionados ao movimento educacional inclusivo, tem o intuito de contribuir para o aprimoramento do processo de formação de tais profissionais.

Temos claramente que tais recomendações não devem se constituir num receituário ou manual de formação, mas podem possibilitar a visibilidade de conhecimentos úteis à prática docente, visto que é unânime a indicação da necessidade de formação dos professores, porém muitas vezes, não se tem clareza de como esse processo dever se organizado e os conteúdos que devem contemplar, seja na Formação Inicial, continuada e/ou em serviço. Victor (2011, p. 101) analisa que "[...] o papel do professor para atender a inclusão escolar não se resume na indicação de uma lista de conhecimentos necessários à sua formação diante de situações complexas [...]".

Destacamos a importância de pesquisas que se debruçam sobre os saberes docentes relacionados à Educação Inclusiva, primeiro porque é um tema de pesquisa pouco explorado pela produção acadêmica da área conforme observou Miranda (2011). Segundo, porque consideramos importante analisar os possíveis 
conhecimentos específicos que possam favorecer o desenvolvimento acadêmico dos alunos com NEE.

\section{MÉTODO}

\subsection{CARACTERIZAÇÃO E DELIMITAÇÃO DO CAMPO DE PESQUISA}

A pesquisa apresenta um delineamento de levantamento e caracteriza-se como documental. Realizamos o levantamento das fontes informacionais, que se constituiu de teses e dissertações produzidas em programas de pós-graduação da área da Educação e da Educação Especial no Brasil, defendidas entre os anos de 2005 e 2010, disponíveis no Banco de Teses da Capes que estiveram voltadas para o processo de inclusão de alunos com NEE no sistema Regular de Ensino e para a Formação Inicial, continuada ou em serviço de professores atuantes junto aos alunos com NEE.

\subsection{PROCEDIMENTOS DE COLETA DE DADOS}

A identificação das fontes informacionais foi realizada entre os meses de Setembro a Dezembro de 2011. Iniciamos a coleta de dados na página de pesquisa do Banco de Teses da Capes, seguindo as seguintes etapas e critérios de seleção: 1) busca pelo descritor "educação inclusiva"; 2) selecionando pesquisas defendidas entre os anos de 2005 e 2010; 3) pesquisas cujo título tivesse as seguintes palavras: educação inclusiva, inclusão, inclusão escolar, inclusão educacional, escola inclusiva, deficiência, necessidades educacionais especiais, educação especial, formação de professores, saberes dos professores, entre outras, que julgamos que pudessem tratar do nosso objetivo de pesquisa; 4) Pesquisas em nível de Mestrado ou Doutorado; 5) Pesquisas que estivessem voltadas para a Educação Infantil e Ensino Fundamental I e II; 6) Pesquisas desenvolvidas em escolas públicas; 7) Pesquisas que focalizavam o professor do Ensino Regular que atendiam alunos com NEE; 8) Pesquisas voltadas para a Formação Inicial (em cursos de graduação em Pedagogia) 
continuada ou em serviço de professores relacionados à formação para inclusão de alunos com NEE.

Com base nesses critérios, selecionamos um total de 140 pesquisas constituídas em 27 teses e 113 dissertações que tratavam das questões referentes à formação de professores, práticas pedagógicas e saberes docentes, pertinentes ao processo de inclusão dos alunos com NEE. Das 140 pesquisas identificadas, foi possível a análise de apenas 121 delas, em decorrência da dificuldade de acesso aos arquivos eletrônicos de 19 pesquisas.

A análise de cada documento (no formato PDF) aconteceu por meio da leitura flutuante do material escrito e a extração automática de termos, conforme explica DE LUCCA (2006). Os termos escolhidos para a busca foram: educador, educadores, docente, docentes, professor, professores, profissional, profissionais. Estes termos eram digitados, na ordem supracitada, no campo específico chamado "search" do Programa Adobe Reader. Com esse programa, foram selecionadas as frases que continham os termos de busca acima mencionados e, à vista disso, analisamos cada uma delas a fim de identificarmos as que continham indicações diretas ou indiretas sobre saberes e práticas docentes favorecedores de uma proposta educacional inclusiva. Em relação ao nosso objetivo de estudo, dentre tantas mensagens que compõem os textos das pesquisas, foram alvo desse artigo, as frases nas quais os autores inferiam sobre o que os professores precisam saber, fazer e até mesmo ser e as características pessoais desejáveis nos professores para realizar a inclusão de alunos com NEE no sistema regular de ensino.

\subsection{TRATAMENTO DOS DADOS}

A partir da compreensão de que a Análise de Conteúdo permite extrair das mensagens sentidos implícitos que ajudam a entender a mensagem em si, elegemos este procedimento metodológico para o tratamento e análise dos dados coletados. Conduzimos essa etapa do estudo segundo as orientações de Bardin (2006).

Para a organização das categorias de análise, baseamo-nos nas análises tecidas por Rodrigues (2008b), pesquisador que é referência na área de Educação Especial em relação à formação de professores para inclusão de alunos com NEE, o 
qual concebeu "saberes, competências e atitudes" como as três principais dimensões implicadas na formação, tantos os professores do ensino comum para promoverem a educação inclusiva, quanto para capacitar os próprios especialistas em Educação Especial e em Tardif (2004) que também considera que os saberes docentes envolvem conhecimentos, habilidades ou aptidões e atitudes. Pesquisadores da área da didática como Grillo (1993); Saviani (1996); Pimenta (2000) contribuíram para a identificação e categorização dos saberes identificados, uma vez que, embora apresentem perspectivas teóricas distintas, compreendem e conceituam os saberes docentes em categorias muitos parecidas.

\section{RESULTADOS E DISCUSSÃO}

Considerando os objetivos propostos, as recomendações de Bardin (2006) referentes à Análise de Conteúdo e a configuração dos dados, os saberes identificados foram organizados em temas que, por sua vez, foram divididos em categorias. Apresentamos, no quadro abaixo, os temas organizados, o que leva em consideração a frequência de pesquisadores que os citaram, bem como a quantidade de frases associadas a cada um dos temas

Quadro 1: Disposição dos números de pesquisadores e quantidade de frases ou parágrafos de cada tema.

\begin{tabular}{|l|c|c|}
\hline \multicolumn{1}{|c|}{ Tema } & Número de pesquisadores & $\begin{array}{c}\text { Quantidade de frases ou } \\
\text { parágrafos }\end{array}$ \\
\hline 1 Dimensão Atitudinal & 64 & 222 \\
\hline 2 Dimensão Procedimental & 64 & 220 \\
\hline $\begin{array}{l}\text { 3 Características pessoais do } \\
\text { professor }\end{array}$ & 48 & 122 \\
\hline 4 Dimensão Conceitual & 41 & 86 \\
\hline 5 Dimensão Contextual & 20 & 30 \\
\hline Total & & 680 \\
\hline
\end{tabular}

Fonte: Elaboração própria.

Como mostra o quadro 1 , os saberes mais frequentemente indicados pelos pesquisadores analisados foram aqueles associados às dimensões atitudinal e procedimental. $\mathrm{Na}$ sequência, encontramos as dimensões referentes às características do professor, conceitual e a contextual. A seguir, apresentaremos as análises sobre os temas e suas respectivas categorias, levando em consideração a frequência com que foram identificados. 


\subsection{TEMA 1 - DIMENSÃO ATITUDINAL}

Organizamos, nesse tema, as indicações dos autores que remetiam às atitudes dos professores. Segundo Saviani (1996, p. 148), o saber atitudinal compreende:

[...] o domínio dos comportamentos e vivências consideradas adequadas ao trabalho educativo. Abrange atitudes e posturas inerentes ao papel atribuído ao educador, tais como disciplina, pontualidade, coerência, clareza, justiça e eqüidade, diálogo, respeito às pessoas dos educandos, atenção às suas dificuldades etc. Trata-se de competências que se prendem à identidade e conformam a personalidade do educador mas que são objeto de formação por processos tanto espontâneos como deliberados e sistemáticos.

Quadro 2- Categorias da Dimensão Atitudinal, quantidade de pesquisadores e frases citadas em cada categoria.

\begin{tabular}{|l|c|c|}
\hline \multicolumn{1}{|c|}{ Categorias } & $\begin{array}{c}\text { Quantidade de } \\
\text { pesquisadores }\end{array}$ & $\begin{array}{c}\text { Quantidade de } \\
\text { frases/parágrafos }\end{array}$ \\
\hline $\begin{array}{l}1.1 \text { Valorizar a diferença e a heterogeneidade, } \\
\text { acreditar no potencial dos alunos e estimular o } \\
\text { desenvolvimento deles }\end{array}$ & 41 & 76 \\
\hline $\begin{array}{l}1.2 \text { Ter responsabilidade pedagógica: compromisso } \\
\text { com o desenvolvimento e aprendizagem dos alunos }\end{array}$ & 32 & 46 \\
\hline 1.3 Dispor-se a ressignificar conceitos e práticas & 29 & 46 \\
\hline $\begin{array}{l}1.4 \text { Dispor-se a estar em processo contínuo de } \\
\text { autoformação, formação continuada ou em serviço }\end{array}$ & 26 & 39 \\
\hline 1.5 Dispor-se à alteridade & 6 & 7 \\
\hline 1.6 Ser favorável à Educação Inclusiva & 6 & 7 \\
\hline 1.7 Dispor-se a buscar apoio & 1 & 1 \\
\hline Total & - & 222 \\
\hline
\end{tabular}

Fonte: Elaboração própria.

Como mostra o quadro 2, os pesquisadores apontaram que a valorização da diferença e da heterogeneidade em sala de aula, a crença de que o aluno pode aprender e o estímulo para o seu desenvolvimento são atitudes importantes para os professores atuantes numa perspectiva inclusiva. A atitude positiva do professor frente à diferença é uma variável significativa para a atuação em contextos educacionais inclusivos com vistas ao combate de qualquer tipo de discriminação e em prol da valorização e do respeito às diversidades humanas que trazem consequência para o processo de aprendizagem.

O trabalho com a diferença na escola não está restrito ao espaço da sala de aula, ela demanda da participação de toda a comunidade escolar e só ganha sentido quando atrelado ao compromisso político, histórico e social que os professores devem ter para com o desenvolvimento acadêmico de todos os alunos. Além disso, há a 
indicação por parte de alguns pesquisadores de que lidar com a diversidade exige também uma análise crítica por parte do professor, uma vez que ele deve ter conhecimento dos processos históricos e sociais que discriminam e estigmatizam as pessoas deficientes (CONCEIÇÃO; KRUG, 2009; FAITANIN, 2010).

Corrêa e Stauffer (2008, p. 214) alertam que não foi a escola pública que inventou a exclusão escolar, está se desenvolveu ao longo da história humana. Nesse sentido, o trabalho pedagógico com a valorização da diferença resgata valores humanos de respeito e solidariedade e princípios ético-profissionais que exigem do professor o compromisso com o desenvolvimento acadêmico e social de todos os seus alunos.

A responsabilidade pedagógica do professor, citada pelos pesquisadores, está atrelada à sua função social, ou seja, à disseminação e mediação dos conhecimentos científicos, sistematizados, historicamente construídos para/com os alunos e portanto, não é exclusivamente do professor da sala de aula comum, pois essa responsabilidade precisa ser compartilhada pelos demais profissionais da escola.

Alves (2010) e Torres (2009) analisaram que o professor não precisa assumir funções que não são suas, mas precisam saber quais são de sua responsabilidade e fazer o possível para colocá-las em prática, o que conta com os recursos necessários para a realização do seu trabalho. Nesse sentido, o desenvolvimento do aluno não pode ser entendido como compromisso exclusivo do professor e essa percepção, alivia-o da sobrecarga de tarefas e expectativas que the são incumbidas com a inclusão escolar e com tantas outras demandas que a educação de um modo geral tem exigido dos professores. Através dessa indicação, deriva-se outras que iremos discutir mais à frente que estão relacionadas com a atitude do professor de buscar apoio e atuar de modo colaborativo junto aos demais profissionais da escola e outros especialistas.

Ressignificar conceitos e práticas é, na nossa avaliação, abrir mão de práticas homogeneizadoras. Os professores não precisam mudar as formas de ensinar e sim diversificá-las para que contemplem em sua prática pedagógica as formas diversificadas de aprender. Essa afirmação é corroborada por (ALMEIDA, 2007; BORTOLOZZO, 2007; COELHO, 2008), entre outros, os quais avaliam que não é necessário somente a ressignificação daquilo que os professores já sabem, mas 
também a aquisição de novos conhecimentos para atender às demandas de um novo contexto educacional bem como o desenvolvimento de atitudes positivas em face da diversidade dos alunos que frequentam a escola.

As mudanças desejadas não dizem respeito somente àquelas que envolvem o trabalho solitário do professor, o modo como é organizada a dinâmica da escola também deve ser ressignificada para que os profissionais inseridos, nela, trabalhem de maneira mais articulada, solidária e cooperativa.

Quanto à indicação de que os professores precisam dispor-se a estar em processo contínuo de autoformação, formação continuada ou em serviço (DALFORNO, 2005), embora seja uma condição inerente ao magistério, avaliamos que não deve ficar a cargo somente dos professores o investimento por uma formação específica que o prepare para o atendimento aos alunos com NEE. É de responsabilidade dos sistemas de ensino propiciar ações formativas dos professores que estão em serviço. O estado não pode ser isento de tal responsabilidade.

Assim como Silva (2008), percebemos que a formação continuada é um espaço extremamente importante, pois é onde acontece a atualização dos profissionais que estão no exercício de suas funções docentes. Contudo, defendemos que a Formação Inicial deve ser repensada a fim de que os profissionais, ao saírem das universidades, não fiquem a mercê apenas de cursos de formação pontuais para o atendimento dos alunos com NEE, mas que também tenham condições mínimas de realizar os procedimentos necessários para o ensino-aprendizagem dos alunos com NEE.

Dispor-se à alteridade, ou seja, a capacidade que o professor tem de se colocar no lugar do outro nas relações interpessoais, é um fator preponderante para a efetivação de processos educacionais inclusivos, assim como observaram Omote et al. (2005) e Sant'Ana (2005).

Pesquisadores têm apontado que a atitude em prol da inclusão é um dos fatores determinantes para o sucesso de tal proposta (OMOTE et al., 2005). Acreditamos que o posicionamento em prol ou contra a inclusão não é estático, uma vez que os professores estão em constante processo de ressignificação e construção de sua identidade pessoal e profissional.

Sobre a disponibilidade dos professores buscarem apoio para a superação de suas dificuldades, essa atitude depende de fatores como: as condições e recursos 
humanos e materiais que a escola dispõe o conhecimento que o professor tem sobre os pressupostos legais que fundamentam a educação inclusiva, pois, para buscar apoio, é importante que ele saiba quem pode dar suporte para sua atuação. No entanto, convém destacarmos que o conhecimento da legislação é importante, mas não garante as condições e os recursos que o professor precisa.

Convém observarmos que nem sempre os professores encontram na própria escola o apoio necessário para a minimização de suas dificuldades. Nesse sentido, conhecendo a especificidade do trabalho dos especialistas no processo educacional inclusivo e reconhecendo que eles possuem uma gama de conhecimentos acumulados sobre as especificidades da educação das pessoas com NEE, o professor pode estabelecer parceria com esses profissionais para o aprimoramento de seu trabalho.

\subsection{TEMA 2- DIMENSÃO PROCEDIMENTAL}

Neste tema, foram organizadas as frases que remetiam ao que Grillo (1993) denominou como dimensão técnica da profissão docente, refere-se ao "fazer", o conhecimento didático-pedagógico e as habilidades necessárias para saber ensinar. Rodrigues (2008b) explicou que esses conhecimentos são necessários para que os professores conduzam com sucesso práticas pedagógicas verdadeiramente inclusivas em contextos diversificados.

Quadro 3- Categorias da Dimensão Procedimental, quantidade de pesquisadores e de frases citadas em cada categoria.

\begin{tabular}{|l|c|c|}
\hline \multicolumn{1}{|c|}{ Categorias } & $\begin{array}{l}\text { Quantidade de } \\
\text { pesquisadores }\end{array}$ & $\begin{array}{c}\text { Quantidade de } \\
\text { frases/parágrafos }\end{array}$ \\
\hline $\begin{array}{l}\text { 2.1 Identificar e atender as necessidades educacionais } \\
\text { de cada aluno }\end{array}$ & 36 & 71 \\
\hline $\begin{array}{l}\text { 2.2 Proceder ao planejamento das aulas, as adaptações } \\
\text { e/ou diferenciação curricular e a avaliação dos alunos } \\
\text { com NEE }\end{array}$ & 26 & 37 \\
\hline $\begin{array}{l}\text { 2.3 Desenvolver práticas pedagógicas inovadoras e } \\
\text { diversificadas }\end{array}$ & 26 & 42 \\
\hline $\begin{array}{l}\text { 2.4Trabalhar coletivamente/ } \\
\text { cooperativamente com professores e alunos }\end{array}$ & 18 & 19 \\
\hline Estabelecer relações teórico/práticas & 13 & 15 \\
\hline $\begin{array}{l}\text { 2.5 Desenvolver um clima emocional e afetivo positivo } \\
\text { em sala de aula em relação aos alunos com NEE }\end{array}$ & 11 & 11 \\
\hline 2.6 Adquirir conhecimentos didático-pedagógicos & 9 & 9 \\
\hline $\begin{array}{l}\text { 2.7 Promover procedimentos que visem à socialização e } \\
\text { respeito entre os alunos }\end{array}$ & 8 & 12 \\
\hline
\end{tabular}




\begin{tabular}{|l|c|c|}
\hline $\begin{array}{l}2.8 \text { Proceder à avaliação e organização do espaço físico } \\
\text { da sala de aula }\end{array}$ & 2 & 4 \\
\hline Total & - & 220 \\
\hline
\end{tabular}

Fonte: Elaboração própria.

Trinta e seis pesquisadores apontaram que o professor é um dos responsáveis pela identificação e atendimento às NEE dos alunos, tendo em vista que é na sala de aula, durante a realização das atividades, que as suas dificuldades são explicitadas e devem ser atendidas. Ponderamos que o conhecimento científico sobre as NEE se faz necessário para essa identificação, caso contrário o que pode ocorrer é a dissimulação das dificuldades observadas ou mesmo a criação de rótulos e encaminhamentos pedagógicos inadequados com base em conhecimentos de senso comum.

Por outro lado, conforme lembrou Omote (2006, p. 256), "a tão recomendada individualização da instrução, no sentido de adequação dos procedimentos a cada aluno e observância de seu ritmo de aprendizagem torna-se quase impraticável numa classe numerosa". Nesse sentido, o autor afirma que um dos grandes desafios da proposta educacional inclusiva é a dificuldade da escola em lidar com a heterogeneidade e as diferenças individuais de cada aluno.

Sobre a categoria "proceder ao planejamento das aulas, às adaptações e/ou diferenciação curricular e à avaliação dos alunos com NEE”, Abreu e Masetto (1985) esclareceram que o planejamento dá ao professor a possibilidade de flexibilização dos objetivos de acordo com as necessidades individuais dos alunos que possam ter maior dificuldade.

Foi interessante observar que, entre as habilidades que o professor deve desenvolver, estão as de promover a socialização entre os alunos, visando à construção de um clima emocional positivo, a cooperação e o respeito. Visto que, tal recomendação, evidencia que os aspectos afetivos e emocionais devem ser levados em conta no planejamento e na ação do professor em sala de aula, dado sua importância no processo de desenvolvimento, motivação e aprendizagem dos alunos.

Sobre a indicação da necessidade do professor aprender a trabalhar de modo cooperativo/colaborativo, há vasta literatura indicando que esse é um dos melhores recursos para favorecer o processo de inclusão. Para ser efetivo o trabalho do professor regente, do professor de apoio aos alunos com NEE na classe comum, dos 
professores especialistas das salas de recursos multifuncionais, bem como da equipe que compõem a gestão escolar deve se dar por meio de troca de informações, recursos e planejamento coletivo visando à organização de condições de ensino que promovam a aprendizagem, socialização e participação dos referidos alunos (MENDES; VILARONGA; ZERBATO, 2014; MARTINELLI, 2016; PRADO, 2016).

De modo geral, os saberes procedimentais indicados evidenciaram os elementos a serem considerados do fazer pedagógico do professor: o espaço físico, o clima emocional da sala de aula, as condições de ensino disponibilizadas, em termos de adaptações pedagógicas, as quais envolvem recursos materiais e humanos, bem como a forma que tais elementos devem ser organizados. Identificamos que essas recomendações estão atreladas aos fundamentos da educação inclusiva, a qual tem como objetivo oferecer aos alunos com NEE, possibilidades de acesso ao currículo, oportunidades/condições que garantam sua permanência na escola com sucesso, permitindo-lhes ainda se sentirem valorizados e respeitados.

\subsection{TEMA 3- CARACTERÍSTICAS PESSOAIS DO PROFESSOR QUE FAVORECEM} A INCLUSÃO DE ALUNOS COM NEE

Organizamos nesse tema as seis categorias compostas pelas frases dos pesquisadores que indicaram as características pessoais dos professores que favorecem a inclusão dos alunos com NEE. Reiteramos que, para nós, todas as características citadas são interdependentes e inter-relacionadas na pessoa do professor, elas só foram separadas para fins de análise.

Quadro 4- Categorias do tema - Características pessoais do professor que favorecem a inclusão de alunos com NEE, quantidade de pesquisadores e frases citadas em cada categoria.

\begin{tabular}{|l|c|c|}
\hline \multicolumn{1}{|c|}{ Categorias } & $\begin{array}{c}\text { Quantidade de } \\
\text { pesquisadores }\end{array}$ & $\begin{array}{c}\text { Quantidade de } \\
\text { frases/parágrafos }\end{array}$ \\
\hline 3.1 Ser um professor que reflete sobre sua prática & 28 & 46 \\
\hline 3.2 Ser crítico & 16 & 22 \\
\hline 3.3 Ter autonomia & 14 & 21 \\
\hline 3.4 Ser criativo & 9 & 11 \\
\hline 3.5 Ser flexível & 10 & 10 \\
\hline 3.6 Ter autoconhecimento & 6 & 12 \\
\hline Total & - & 122 \\
\hline
\end{tabular}

Fonte: Elaboração própria. 
Freire (1996) já considerava que a reflexão crítica sobre a prática torna-se uma exigência ao educador para que haja o estabelecimento da práxis pedagógica. Para ele, sem essa ação reflexiva a teoria pode vir a ser menosprezada e a prática pedagógica se tornar ativismo.

Victor (2011, p. 94) acrescenta que as situações vivenciadas pelos professores em diferentes contextos educativos geram uma forma de reflexão que está associada além de problemas de ordem prática, também aos seus valores, pois são situações "únicas, complexas e variadas", que requerem um conjunto de teorias para ajudar o professor a elucidá-las. Estas análises reafirmam a ideia de que a reflexão não deve acontecer, tendo como base apenas as situações práticas, mas ter como eixo subsídios teóricos que auxiliam o professor a compreender e a ressignificar seu saberfazer.

A capacidade do professor analisar, avaliar, julgar e criticar atitudes, concepções, ideologias (suas e de outrem), o contexto político-social e as políticas educacionais foi denominada de "criticidade". Avaliamos, com base em Freire (1996), que o pensamento crítico que supera a curiosidade ingênua tem que ser construído ao longo de todo processo formativo do professor.

A criticidade faz-se necessária, inclusive, para que os professores avaliem como tem sido implementada a política educacional inclusiva na sua própria realidade, avaliando se os subsídios humanos, físicos e materiais necessários para a sua efetivação têm sido respeitados, visando a possíveis alternativas e encaminhamentos junto aos demais profissionais da escola para que os direitos dos alunos de terem espaço físico apropriado, materiais de apoio necessários e professores qualificados para atenderem suas necessidades sejam respeitados.

A autonomia citada pelos pesquisadores refere-se à necessidade de os professores terem independência em seus fazeres cotidianos para pensar, planejar e intervir pedagogicamente junto aos seus alunos, de forma a atender suas necessidades, prescindindo de planejamentos e métodos estabelecidos, a priori, do conhecimento da realidade escolar.

Contudo, alertamos para que a autonomia docente não seja entendida como liberdade absoluta sobre o que ensinar, uma vez que existem documentos legais e normativos comuns ao sistema nacional, estaduais e municipais de ensino, bem como 
a proposta pedagógica de cada instituição escolar que devem nortear o trabalho do professor.

Especialmente quando falamos de educação inclusiva e de adaptação curricular, o professor precisa compreender os limites de sua autonomia no processo de adaptação do currículo, uma vez que os alunos com NEE não devem ter acesso apenas aos conhecimentos que o professor julga necessário, mas sim aos mesmos conteúdos que os demais alunos têm, embora necessitem, muitas vezes, de metodologias e materiais diversificados.

A autonomia docente deve ser entendida como a capacidade do professor de identificar as suas dificuldades e necessidades e de seus alunos para buscar meios de superar esses entraves, ainda que, para isso, precise contar com o apoio de outros profissionais da escola.

No que tange à criatividade, refere-se, na perspectiva dos pesquisadores, como um dos requisitos essenciais para o desenvolvimento de uma educação com qualidade, uma vez que o cotidiano da sala de aula exige muitas vezes que o professor tenha a capacidade de solucionar criativamente os problemas enfrentados na prática pedagógica. Compreendemos que a criatividade é reflexo das experiências acumuladas pelo professor enquanto profissional e de suas características pessoais, mas também que a capacidade criativa é influenciada pelas possibilidades de acesso a diferentes recursos que a escola, dentro de sua infraestrutura, pode disponibilizar para a realização de seu trabalho.

Ser uma pessoa flexível configura-se como uma necessidade dos professores que atuam em salas de aula inclusivas, segundo as análises de dez pesquisadores. A flexibilidade necessária ao professor é aquela que lhe permite, no decorrer das situações, agir de modo a reorganizar seu planejamento, as atividades propostas, os procedimentos de ensino.

Pesquisadores como Farias et al. (2009) indicaram que a organização geral do processo didático deve ser flexível. Práticas pedagógicas engessadas por determinadas teorias ou métodos de ensino não favorecem a aprendizagem e desenvolvimento do aluno. Contudo, ao primeiro contato com o aluno com NEE e suas dificuldades ou exigências específicas no processo de ensino, o professor pode enfrentar dificuldades em ser flexível, principalmente se este não tiver conhecimentos 
específicos sobre a deficiência do aluno, bem como de estratégias variadas de ensino. Dessa forma, consideramos que a flexibilidade pode se constituir numa característica que depende dos outros conhecimentos que o professor possa ter a respeito de seu aluno e de metodologias de ensino.

Sobre o autoconhecimento, avaliamos que ele seja um elemento importante ao professor para o processo de reflexão e criticidade sobre a própria prática, pois ao reconhecer suas concepções, ideologias, valores e preconceitos o professor tem indicadores dos aspectos pessoais que interferem negativamente em seu trabalho com os alunos que apresentam NEE e que precisam ser trabalhados para que sua atuação, junto a eles, atinja o objetivo pretendido.

\subsection{TEMA 4- DIMENSÃO CONCEITUAL}

Nesse tema organizamos as frases que se referiram aos conhecimentos do campo teórico-científico dos professores, considerados saberes conceituais que fundamentam a ação pedagógica do professor. Rodrigues (2008b, p. 12) explicou que esses conhecimentos:

[...] vão desde aspectos mais diretamente teóricos, tais como o contacto com o pensamento e a teorização de diferentes autores, até (e sobretudo) trabalhos de investigação feitos em contextos reais que possam fundamentar a adoção de determinadas opções metodológicas.

Quadro 5- Categorias da Dimensão Conceitual, quantidade de pesquisadores e frases citadas em cada categoria.

\begin{tabular}{|l|c|c|}
\hline \multicolumn{1}{|c|}{ Categorias } & $\begin{array}{c}\text { Quantidade de } \\
\text { pesquisadores }\end{array}$ & $\begin{array}{c}\text { Quantidade de } \\
\text { frases/parágrafos }\end{array}$ \\
\hline $\begin{array}{l}4.1 \text { Ter conhecimentos específicos sobre as } \\
\text { deficiências e as NEE }\end{array}$ & 23 & 40 \\
\hline $\begin{array}{l}4.2 \text { Conhecimento das teorias de desenvolvimento } \\
\text { humano e de aprendizagem }\end{array}$ & 11 & 12 \\
\hline $\begin{array}{l}\text { 4.3 Conhecer a legislação e lutar pelos seus direitos } \\
\text { e dos alunos com NEE }\end{array}$ & 7 & 7 \\
\hline $\begin{array}{l}\text { 4.4 Conhecer e compreender a importância dos } \\
\text { pressupostos da educação inclusiva }\end{array}$ & 7 & 17 \\
\hline $\begin{array}{l}\text { 4.5 Conhecer sobre o uso das tecnologias para o } \\
\text { ensino }\end{array}$ & 6 & 86 \\
\hline Total & - & 10 \\
\hline
\end{tabular}

Fonte: Elaboração própria.

Na categoria "Ter conhecimentos específicos sobre as deficiências e as NEE", organizamos as indicações dos pesquisadores a respeito da necessidade de que os 
professores tenham conhecimento das NEE de modo geral, em relação à surdez e Libras, as características da deficiência mental, paralisia cerebral e sobre as Altas Habilidades/Superdotação (AH/SD).

Concordamos com as análises de Macedo (2010) ao afirmar que o professor do Ensino Regular não necessita conhecer com profundidade todos os tipos de deficiência e os códigos utilizados na comunicação de alguns grupos de pessoas com esse problema em questão, mas é necessário algum conhecimento sobre eles para que consiga compreender esses alunos e organizar procedimentos de ensino que favoreçam sua aprendizagem.

Em relação ao conhecimento sobre as deficiências, Prioste (2006) e Rodrigues (2008a) alertam para o fato de que, embora seja importante que o professor conheça as características das deficiências, é imprescindível que ele não se fixe nelas, tendo em vista que propostas de ensino pautadas nas limitações provocadas pela deficiência, numa perspectiva clínica, não favorecem o desenvolvimento acadêmico dos alunos com NEE.

A escola regular deve se ocupar com propostas de cunho pedagógico, pois cabe aos profissionais que compõem as equipes multidisciplinares ocuparem-se dos aspectos clínicos da deficiência e desenvolverem meios de minimizar as dificuldades por ela ocasionadas.

Sobre a necessidade de o professor conhecer teorias sobre desenvolvimento humano e da aprendizagem, os pesquisadores destacaram que é importante que os professores dominem tais conhecimentos para atuar junto aos alunos com NEE, visto que podem ajudá-los a identificar e escolher os materiais e os procedimentos mais adequados no processo de ensino e aprendizagem e nas adaptações curriculares, a fim de suprir as necessidades educacionais dos alunos.

Nos dias atuais, tendo em vista os pressupostos da educação inclusiva e a necessidade de se formar professores que incluam seus alunos com NEE, Vitaliano e Manzini (2010) comentam que os cursos de Formação de Professores devem priorizar conteúdos que enfatizem as causas ambientes como fatores determinantes e apontar para possibilidades de análise das deficiências que vinculem a percepção de que a deficiência é também uma leitura social das características peculiares de cada sujeito. 
Sete pesquisadores consideraram importante $\mathrm{o}$ professor conhecer a legislação referente ao processo de inclusão, bem como os seus direitos e de seus alunos, enquanto quatro pesquisadores avaliaram que o professor deve ter conhecimento da legislação para compreender e interpretar o que ela diz e, assim, retirar dela o que é mais importante.

As análises apresentadas na categoria "conhecer e compreender a importância dos pressupostos da educação inclusiva" indicou a importância de que os professores conheçam os princípios e objetivos de uma proposta educacional, pois quando são levados a colocar em prática um projeto educacional que desconhecem, não se dispõem de forma efetiva a colocá-lo em prática; pensamos que nem sempre isso acontece pelo não querer fazer, mas, sobretudo, pela falta de conhecimentos que possam fundamentar sua prática.

Peterson (2006) e Rodrigues (2008a) avaliaram que os professores devem saber o que compete aos profissionais da educação especial e o que compete à escola regular no processo de inclusão de alunos com NEE.

Rodrigues (2008b) analisou também que os professores devem saber qual a relação que a educação inclusiva estabelece com as escolas especiais e devem ainda valorizar os conhecimentos os quais foram desenvolvidos nessas escolas e que podem ser usados para melhorar a educação de todos os alunos na escola regular e não apenas dos alunos com NEE.

Em relação à necessidade do professor conhecer sobre o uso das tecnologias, os pesquisadores apontaram a necessidade dos professores terem conhecimento sobre as tecnologias da informação e da comunicação (TICs) para que possam utilizálas como meio de ensino para alcançar a aprendizagem dos alunos com NEE.

Observamos que os pesquisadores preocupam-se em apontar que o uso das tecnologias no processo de ensino deve estar associado ao conteúdo e aos objetivos da aula, pois, dependendo do que se pretende ensinar, as ferramentas tecnológicas podem ou não fazer parte de procedimentos pedagógicos as quais atendam as necessidades dos alunos e aos objetivos do professor.

\subsection{TEMA 5- DIMENSÃO CONTEXTUAL}


Essa categoria foi organizada com base nas análises propostas por Saviani (1996), o qual define que o saber crítico-contextual refere-se à compreensão que os professores devem ter sobre as condições sócio-históricas que determinam a tarefa educativa. Para o autor, o professor deve saber detectar as necessidades do presente e do futuro que configuram o processo educativo que está sob sua responsabilidade. A compreensão do contexto no qual e para o qual se desenvolve o processo educativo também compõe essa dimensão.

Também subsidiou a organização desse tema as análises de Grillo (1993), a qual considera que uma das categorias que compõe o fazer docente refere-se à dimensão contextual, o que ela denominou de "o intervir". Essa categoria é composta, segundo a referida autora, pelos aspectos relacionados com a ação políticopedagógica que o professor assume, tendo como objetivo a intervenção e modificação no contexto social, político e econômico no qual está inserido.

Quadro 6- Categorias da Dimensão Contextual, quantidade de pesquisadores e frases citadas em cada categoria.

\begin{tabular}{|l|c|c|}
\hline \multicolumn{1}{|c|}{ Categorias } & $\begin{array}{c}\text { Quantidade de } \\
\text { pesquisadores }\end{array}$ & $\begin{array}{c}\text { Quantidade de } \\
\text { frases/parágrafos }\end{array}$ \\
\hline Ter responsabilidade político-social & 15 & 23 \\
\hline Dialogar com o contexto sociocultural dos alunos & 5 & 7 \\
\hline Total & - & 30 \\
\hline
\end{tabular}

Fonte: Elaboração própria.

Compreendemos que a tarefa educativa é por si mesma um ato político, uma vez que é parte integrante de um processo vital que envolve a formação humana dos sujeitos. Seja numa relação macro ou micro estrutural, a ação pedagógica do professor revela posicionamentos de cunho político, que não significa necessariamente político-partidária, como muitas vezes é entendido, e sim a compreensão de que nenhum ato educativo é neutro, pois pressupõe valores, concepções, ideologias.

Nesse sentido, assumir a responsabilidade política do ato educativo significa assumir uma postura de quem se compromete com uma dimensão crítico-social dos conteúdos escolares que dissemina. Nessa perspectiva teórica, há previsão de que sejam desvelados na prática didático-pedagógica, ao se abordar os conteúdos escolares, os determinantes históricos, políticos, culturais, econômicos, sociais, 
ideológicos, entre outros, que envolvem determinado conteúdo, no que tange à sua produção, disseminação e utilização pelos homens. Significa que o aluno deve saber o quando, onde e o porquê foi elaborado tal conhecimento, qual é a sua finalidade e aplicação prática desse saber para sua vida profissional e social como um todo.

O maior compromisso dos educadores junto a todos os seus alunos, independentemente de suas condições físicas, mentais, biológicas, sociais, entre outras, é propiciar-Ihes o desenvolvimento integral no que cabe à sua função profissional, contudo, sabemos que além do domínio dos conhecimentos específicos que envolvem e permitem o professor ter consciência dessa dimensão, consideramos também que ela é influenciada pelas concepções do professor sobre o mundo, o homem, a sociedade e a educação.

A respeito do diálogo com o contexto sociocultural, refere-se à capacidade do professor em construir, articular e mediar ações entre a escola, a família e a comunidade escolar, haja vista que diante da influência que o professor exerce no alcance dos objetivos da educação inclusiva, suas decisões e ações devem sempre estar consoantes com o contexto em que a prática pedagógica ocorre (SALGADO, 2008).

\section{CONSIDERAÇÕES FINAIS}

Compilamos com este estudo um rol de saberes docentes considerados importantes aos professores para a prática pedagógica junto aos alunos com NEE incluídos no Ensino Regular que, com base na literatura da área foram organizados em cinco dimensões: dimensão atitudinal; dimensão procedimental, dimensão conceitual; dimensão contextual e características pessoais do professor.

Dentre os saberes recomendados, identificamos que a maior parte deles diz respeito às atitudes dos professores que influenciam no processo de inclusão escolar dos alunos com NEE, seguidos dos conhecimentos práticos relacionados ao saberfazer docente, dos conhecimentos teóricos necessários para subsidiar as ações docentes, bem como das características pessoais do professor as quais favorecem tal processo, além dos saberes os quais envolvem a compreensão que os professores devem ter sobre as condições sócio-históricas que determinam a tarefa educativa. 
Todos os saberes agrupados nesse trabalho foram organizados com base nas dimensões consideradas por alguns pesquisadores como importantes ao desenvolvimento profissional do professor, no entanto, consideramos que esses não são saberes isolados, são saberes correlacionados, interdisciplinares e multidimensionais, o que reforça a ideia de que a formação docente deve acontecer num continuum que perpassa a formação inicial, continuada e/ou sem serviço, bem como não se limita a esses espaços dado a importância dos saberes advindos da experiência diária do professor em sala de aula.

É preciso que a formação de professores seja inicial, continuada ou em serviço crie condições para que os professores desenvolvam uma compreensão mais alargada sobre a realidade na qual a educação está circunscrita, bem como das condições materiais sobre as quais o trabalho docente é realizado, além da produção de saberes que promovam o desenvolvimento profissional, numa perspectiva reflexiva, crítica, emancipatória e colaborativa.

Consideramos que as análises dos saberes apresentados nesse artigo não se constituem em um receituário, mas sim numa possível diretriz que visa facilitar a organização de processo de formação de professores com o intuito de favorecer a inclusão dos alunos com NEE. A partir das análises realizadas, vislumbramos que o processo de formação do professor é individual e único, dado o fato de que cada professor tem seu próprio processo de formação e atuação específicos, pois sua construção depende de múltiplos fatores, entre eles está o processo formativo formal, que se entrelaça às suas experiências de vida, à sua forma de perceber o mundo, aos valores que defende, enfim, a diversos aspectos subjetivos de cada um.

Dessa forma, este estudo tem seus limites no sentido de indicar alguns saberes que foram considerados por diversos pesquisadores como importantes na atuação $e$ no processo de formação dos professores para promover a inclusão dos alunos com NEE, mas esses não se esgotam nos resultados ora analisados. Dado a complexidade dos acontecimentos das salas de aula, podemos dizer que, provavelmente outros saberes, ainda não identificados, são igualmente importantes e no futuro poderão ser acrescentados. Além disso, podemos considerar as possibilidades dos professores, enquanto profissionais da educação desenvolverem outros saberes. 
Acreditamos que este estudo poderá servir como ponto de partida para outras pesquisas que se interessem em analisar o perfil do professor inclusivo, como também, para análise dos responsáveis pelas disciplinas nos cursos de Formação de Professores e de cursos de Formação Continuada, para que organizem seus respectivos cursos e disciplinas, levando em consideração os saberes pesquisados e reconhecidos como importantes a favorecer a inclusão de alunos com NEE.

\section{GISLAINE SEMCOVICI NOZI}

Graduada em Pedagogia e Mestra em Educação pela Universidade Estadual de Londrina (UEL). Especialista em Educação Especial Inclusiva (UNOPAR). Doutoranda em Educação na UEL. Professora na rede municipal de Londrina (PR), atuando no Atendimento Educacional Especializado.

\section{CELIA REGINA VITALIANO}

Doutora em Educação pela Universidade do Estado de São Paulo (UNESP). Graduada em Psicologia pela Universidade Estadual de Londrina (UEL). Mestra em Educação Especial (Educação do Indivíduo Especial) (UFSCar).Professora associada da UEL, no Departamento de Educação (Educação Especial).

\section{REFERÊNCIAS}

ABREU, M. C.; MASSETO, M. T. Descrição de algumas estratégias para aprendizagem. In: MG Editores, 1985, p. 61-88. . O professor universitário em aula. 5. ed. São Paulo:

ALMEIDA, A. de A. C. Inclusão escolar e deficiência mental: reflexões e questionamentos em busca de um novo olhar para a diversidade e formação de professores. 2007. 180p. Dissertação (Mestrado em Educação) - Universidade de Uberaba, Uberaba.

ALVES, M. J. de M. A educação inclusiva nas escolas públicas municipais de Anápolis nos anos iniciais do ensino fundamental e a formação docente. 2010. 125p. Dissertação (Mestrado em Educação) - Centro Universitário de Anápolis, Pontifícia Universidade Católica de Goiás, Anápolis.

AZEVEDO, M. C. de C. C de. Os saberes docentes na ação pedagógica dos estagiários de música: dois estudos de caso. 2007. 449p. Tese (Doutorado em Música) - Universidade Federal do Rio Grande do Sul, Porto Alegre. 
BARDIN, L. Análise de Conteúdo. 3. ed. Lisboa, Pt: Edições 70. 2006.

BLOCK, O.; RAUSCH, R. B. Saberes Docentes: dialogando com Tardif, Pimenta e Freire. Revista de Ensino, Educação e Ciências Humanas, v. 15, n. 3, p. 249-254, out. 2014. Disponível em:

$<$ http://revista.pgsskroton.com.br/index.php/ensino/article/view/493>. Acesso em: 08 mar. 2018.

BORGES, C. Saberes docentes: diferentes tipologias e classificações de um campo de pesquisa. Educação \& Sociedade, ano 23, n. 74, p. 59-76, abr. 2001. Disponível em: <http://www.scielo.br/pdf/es/v22n74/a05v2274.pdf>. Acesso em: 08 mar. 2018.

BORTOLOZZO, A. R. S. Banco de dados para o uso das tecnologias de informação e comunicação na prática pedagógica de professores de alunos com necessidades educacionais especiais. 2007. 128p. Dissertação (Mestrado em Educação) Pontifícia Universidade Católica do Paraná, Curitiba.

CARAMÃO, M. T. M. Saberes docentes, avaliação e inclusão: estudo de uma realidade. 2009. 87p. Dissertação (Mestrado em Educação) - Universidade Federal de Santa Maria, Santa Maria.

COELHO, W. L. R. Política maranhense de inclusão escolar: com a palavra, as professoras. 2008. 119p. Dissertação (Mestrado em Educação) - Universidade Federal do Maranhão, São Luís.

CONCEIÇÃO, V. J. S. da; KRUG, H. N. Formação inicial de professores de educação física frente à uma realidade de inclusão escolar. Rev. Educ. Esp., Santa Maria, v. 22, n. 34, p. 237-250, maio/ago. 2009. Disponível em:

<https://periodicos.ufsm.br/educacaoespecial/article/view/276>. Acesso em: 07 mar. 2018.

CORREAA, V. L. A. dos S.; STAUFFER, A de B. Educação Inclusiva: repensando políticas, culturas e práticas na escola pública. In: SANTOS, M. P dos.; PAULINO, M. M. (orgs.). Inclusão em educação: culturas, políticas e práticas. São Paulo: Cortez, 2008. p. 123-142.

DAL-FORNO, J. P. Imaginários e saberes docentes na escola inclusiva: um estudo dos processos de formação e autoformação. 2005. 182p. Dissertação (Mestrado em Educação) - Universidade Federal de Santa Maria, Santa Maria.

DE LUCCA, J. L. Identificação de padrões recorrentes no discurso técnico e científico para a extração automática a candidatos definitórios em Língua Portuguesa. Revista Intercâmbio, São Paulo, vol. 15. 2006. Disponível em: $<$ https://revistas.pucsp.br/index.php/intercambio/article/view/3683>. Acesso em: 02 mar. 2018. 
FAITANIN, G. P. da S. Formação e educação inclusiva: as concepções do Curso de Pedagogia/Universidade Federal Fluminense/Niterói. 2010. 151p. Dissertação (Mestrado em Educação) - Universidade Federal Fluminense, Niterói.

FARIAS, I. M. S. et al. A organização do processo didático. In: . Didática e docência. Aprendendo a profissão. Brasília: Liber Livros, 2009. p. 101-127.

FERRAZ, R. D. Saberes docentes: constituição e mobilização dos saberes experienciais frente à inclusão em sala de aula de alunos com deficiência mental. 2008. 153 p. Dissertação (Mestrado em Educação) - Universidade Federal de Uberlândia, Uberlândia.

FREIRE, P. Pedagogia da autonomia: saberes necessários à prática educativa. 34 ed. São Paulo: Paz e Terra, 1996. 148 p.

GUASSELLI, M. F. R. Dizeres, saberes e fazeres do professor, no contexto da inclusão escolar. 2005.109p. Dissertação (Mestrado em Educação) - Faculdade de Educação. Universidade Federal do Rio Grande do Sul, Porto Alegre.

GRILLO, M. C. Qualidade do ensino superior- Estudo do referencial pedagógico de professores. $16^{a}$ Reunião Anual da ANPED. Caxambu, MG. 12 a 17 de Setembro de 1993. Disponível em:

https://documentcloud.adobe.com/link/track?uri=urn\%3Aaaid\%3Ascds\%3AUS\%3A6 24fea4e-530b-4232-a45b-b51db586e4d5. Acesso em: 18 ago. 2019.

JESUS, M. L. T. B. de. Saberes necessários ao professor: uma aproximação do conceito de autonomia e das suas implicações para o desenvolvimento da profissão docente. 2004. 145p. Dissertação (Mestrado em Educação) - Faculdade de Educação. Universidade Federal da Bahia, Salvador.

MACEDO, N. N. Formação de professores para a educação inclusiva nos cursos de Pedagogia das universidades públicas paulistas. 2010.140p. Dissertação (Mestrado em Educação Especial) - Centro de Educação e Ciências Humanas. Universidade Federal de São Carlos, São Carlos.

MARTINELLI, J. A. Trabalho colaborativo entre uma professora especialista e professores do ensino comum para inclusão de alunos com necessidades educacionais especiais. 2016. 154p. Dissertação (Mestrado em Educação) Universidade Estadual de Londrina, Londrina.

MENDES, E.G.; VILARONGA, C.A.R.; ZERBATO, A. P. Ensino Colaborativo como apoio à Inclusão Escolar. Unindo esforços entre educação comum e especial. 1. ed. v. 1, São Carlos: EDUFSCar, 2014. 162 p.

MIRANDA, T. G. Desafios da formação: dialogando com pesquisas. In: CAIADO, K. R. M.; JESUS, D.M de.; BAPTISTA, C. R. (orgs.). Professores e Educação Especial: formação em foco. Porto Alegre: Mediação/CDV/FACITED, v. 1. 2011. p. 125-141. 
NUNES, C.M.F. Saberes docentes e formação de professores: um breve panorama da pesquisa brasileira. Educação \& Sociedade, ano 23, n. 74, Abr. 2001. Disponível em: <http://www.scielo.br/pdf/es/v22n74/a03v2274.pdf>. Acesso em: 14 jan. 2018.

OMOTE, S. et al. Mudança de atitudes sociais em relação à inclusão. Paidéia.

Ribeirão Preto. v. 15, n. 32, p. 387-398, dez. 2005. Disponível em:

<http://www.scielo.br/pdf/paideia/v15n32/08.pdf>. Acesso em 08 jul. 2017.

OMOTE, S. Inclusão e a questão das diferenças na educação. Perspectiva, Florianópolis, v. 24, n. Especial, p. 251-272, jul./dez. 2006. Disponível em: $<$ https://periodicos.ufsc.br/index.php/perspectiva/article/view/10589>. Acesso em: 08 jul. 2017.

PETERSON, P. J. Inclusão nos Estados Unidos: filosofia, implementação e capacitação de professores. Rev. Bras. Educ. Espec., Marília, v. 12, n. 1, Abr. 2006. Disponível em: $<$ http://www.scielo.br/pdf/rbee/v12n1/31981.pdf >. Acesso em: 31 ago. 2017.

PIMENTA, S. G. Formação de professores: identidade e saberes da docência. In:_ (org.). Saberes pedagógicos e atividade docente. 2 ed. São Paulo: Cortez, 2000. p. 15-34.

PRADO, D. N. M. Professor de apoio: caracterização desse suporte para a inclusão escolar numa rede municipal de ensino. 2016. 162p. Dissertação (Mestrado em Educação) - Universidade Estadual de Londrina, Londrina.

PRIOSTE, C. D. Diversidade e adversidades na escola. Queixas e conflitos de professores frente à educação inclusiva. 2006. 83p. Dissertação (Mestrado em Educação) - Faculdade de Educação. Universidade de São Paulo, São Paulo.

RODRIGUES, D. Questões preliminares sobre o desenvolvimento de políticas de Educação Inclusiva. Inclusão: Rev. Educ. Esp., Brasília, v. 4, n. 1, p. 33-40, jan./jun. 2008a. Disponível em:

$<$ http://portal.mec.gov.br/seesp/arquivos/pdf/revinclusao5.pdf>. Acesso em: 30 ago. 2017.

. Desenvolver a Educação Inclusiva: dimensões do desenvolvimento profissional. Inclusão: Rev. Educ. Esp., Brasília, v. 4, n. 2, p. 7-16, jul./out. 2008b. $<$ http://webcache.googleusercontent.com/search?q=cache:3gWs vAg20EJ:portal.me c.gov.br/index.php\%3Foption\%3Dcom docman\%26task\%3Ddoc download\%26gid \%3D401+\&cd=1\&hl=pt-BR\&ct=clnk\&gl=br $>$ Acesso em: 10 jul. 2017.

SALGADO, S. da S. Inclusão e processos de formação. In: SANTOS, M. P. dos; PAULINO, M. M. (orgs.). Inclusão em educação: culturas, políticas e práticas. São Paulo: Cortez, 2008. p. 59-68. 
SANT'ANA, I. M. Educação inclusiva: concepções de professores e diretores. Psicologia em Estudo, Maringá, v. 10, n. 2, p. 227- 234, ago. 2005. Disponível em: <http://www.scielo.br/pdf/pe/v10n2/v10n2a09.pdf >. Acesso em: 30 ago. 2017.

SANTOS, C. A. de O. Deficiência mental: uma possibilidade de compreensão dos saberes de professores do ensino regular. 2007. 197p. Dissertação (Mestrado em Educação) - Universidade Federal de Uberlândia, Uberlândia.

SAVIANI, D. Os saberes implicados na formação do educador. In: BICUDO, M.A.V; SILVA JUNIOR, C. A. (orgs.). Formação do educador: dever do Estado, tarefa da Universidade. São Paulo: Unesp, 1996. p. 145-155.

SILVA, A. P. da. O professor de Educação Física como agente do processo inclusivo. In: SANTOS, M. P. dos; PAULINO, M. M. (orgs.). Inclusão em educação: culturas, políticas e práticas. São Paulo: Cortez, 2008. p. 69-81.

TARDIF, M. Saberes docentes e formação profissional. Petrópolis: Vozes, 2004.

TORRES, M. P. Políticas de educação e formação de professores: experiências de inclusão no município de São Gonçalo/RJ. 2009. 117p. Dissertação (Mestrado em Educação) - Universidade Federal Fluminense, Niterói.

VICTOR, S. L. Formação inicial e pesquisa-ação colaborativa na UFES. In: CAIADO, K. R. M.; JESUS, D. M. de; BAPTISTA, C. R. (orgs.). Professores e Educação Especial: formação em foco. Porto Alegre: Mediação/CDV/FACITED, v. 1. 2011. p. 91-104.

VITALIANO, C. R.; MANZINI, E. J. A formação inicial de professores para inclusão de alunos com necessidades educacionais especiais. In: (org.). Formação de professores para a inclusão de alunos com necessidades educacionais especiais. Londrina: EDUEL, 2010. p. 49-112. 